ARXIU D'ETNOGRAFIA DE CATALUNYA, N. 3, 1984

\title{
EL MODELO MÉDICO HEGEMÓNICO: TRANSACCIONES Y ALTERNATIVAS HACIA UNA FUNDAMENTACIÓN TEÓRICA DEL MODELO DE AUTOATENCIÓN EN SALUD
}

\author{
Eduardo L. MENÉNDEZ
}

Centro de Investigaciones y Estudios Superiores en Antropología Social, I.N.A.H. (México) 
1. En dos trabajos previos (E. L. Menéndez, 1978 y - 1980) hemos tratado de caracterizar la estructura del modelo médico, así como el proceso contradictorio que el desarrollo del mismo supone. En otros dos materiales hemos tratado de demostrar a nivel empírico la incidencia de los procesos de automedicación, por lo menos para el contexto mexicano (E. L. Menéndez, 1981a y 1982). En este trabajo retomaremos algunos de los conceptos planteados para analizar en particular una de las principales áreas que surge en el proceso de expansión actual del modelo médico hegemónico, y que conforma una potencial alternativa al mismo.

En consecuencia, los objetivos de este trabajo son: indicar que la constitución, crisis y transformación del modelo médico hegemónico (de ahora en adelante $\mathrm{MMH}$ ) depende tanto del sistema dominante como de los procesos transaccionales establecidos entre las clases dominantes y las clases subalternas; que estas transacciones suponen la existencia de prácticas alternativas que el sistema trata de apropiarse en su proceso de expansión; que una de estas prácticas alternativas la constituye la AUTOATENCIÓN EN SALUD, la cual expresa más que ninguna otra la posibilidad transformadora del conjunto de las clases en su relación con la problemtica de salud; que una variante actual de la autoatención la constituyen los diferentes grupos de autoayuda en salud; que el desarrollo de esta alternativa es producto de diferentes factores, entre ellos el fracaso y/o las limitaciones del $\mathrm{MMH}$; que estas alternativas no suponen la existencia «en sí» de un proyecto ideológicopolítico, sino que dicho proyecto se desarrolla, como siempre, en función de los sectores sociales que realmente se hacen cargo de llevar a la práctica las propuestas alternativas.

Estos objetivos serán desarrollados parcialmente a través de dos puntos básicos: I) la emergencia de la autoatención a través de un problema de salud determinado, y II) la propuesta inicial de una fundamentación teórica de los sistemas alternativos de autoatención.

2. En los trabajos anteriores hemos descrito y analizado la expansión del MMH y la transformación operada en los sistemas alternativos como producto parcial de dicha expansión. Pero también hemos analizado cómo 
éste proceso de expansión puede generar cuestionamientos y crisis a partir de derivaciones y productos del mismo $\mathrm{MMH}$ vinculados a procesos potencialmente contradictorios del mismo, así como a procesos establecidos por los sectores dominantes.

Trataremos de ver a través de un caso -el del alcoholismo- las limitaciones y crisis del $\mathrm{MMH}$, así como la emergencia de una forma alternativa basada en la autoayuda. Hemos seleccionado el caso, como es obvio, por estas condiciones, pero también porque va constituyéndose directa o indirectamente en uno de los principales problemas de salud de varios países, incluidos algunos de Latinoamérica. En diversas naciones constituye actual mente la tercera causa de mortalidad; según algunos autores, si se pudiera medir la mortalidad directa e indirecta generada por la ingesta excesiva de alcohol, ocurriría algo similar en países como Argentina, Chile y México

Podemos enumerar como consecuencias negativas de la ingesta de alcohol las siguientes dimensiones: mortalidad y morbilidad directa; morta lidad y morbilidad «indirecta» (cirrosis hepática, accidentes de tráfico, accidentes laborales, homicidios, suicidios, consecuencias en el producto [hijo], etc.); problemas de ingesta de alcohol ligados a violación sexual dentro y fuera de la familia, al síndrome del niño apaleado, a la violencia no sexual dentro y fuera de la familia, a la estructura del gasto y la repercusión diferencial en la alimentación en grupos de mayor riesgo; al absentismo y organización laboral; a gastos de atención directa e indirecta en salud; a fenómenos de control social e ideológico; al costo global (leído generalmente casi en exclusivos términos de productividad). Para tener una idea más o menos esquemática de estos costos, señalemos que para Chile las consecuencias económicas del alcoholismo equivalen a la mitad del total de las exportaciones de cobre; que en los EE.UU. se ha evaluado dicho costo en 43.000 millones de dólares; que en Francia el problema del alcoholismo cuesta a la Seguridad Social 10.000 millones de francos. Subrayemos además que la problemática se está incrementando en casi todos los países para los cuales hay información.

El alcoholismo surge como problema médico-psiquiátrico básicamente a fines del siglo xvır. No obstante tanto desde la psiquiatría como desde la medicina aparecerá en la práctica como un problema de muy «bajo interés». Es retomado como problema médico durante la última parte del siglo xix, pero tan sólo a partir de 1940 podemos decir que se establece una corriente continua de investigaciones y se crean las condiciones para que sea reconocido como enfermedad, básicamente a través del síndrome de dependencia.

No obstante este desarrollo, en la actualidad no se ha podido establecer con claridad qué es el alcoholismo, ni definir con precisión sus tipos o clases más allá de criterios de cantidad y frecuencia. Tampoco se ha logrado establecer indicadores fiables para un diagnóstico precoz del problema. Esta situación resulta aún más confusa para el tratamiento terapéutico, ya que, salvo en el caso de la desintoxicación, los diferentes tipos de tratamiento aparecen como simplemente azarosos.

Esto puede parecer una exageración o sobresimplificación, pero todas las revisiones actuales del problema, aun las más optomistas como la de G. Edwards (1980), establecen este confuso panorama diagnóstico y terapéutico. En una revisión de las definiciones, clasificaciones, indicadores y estrategias terapéuticas realizada por R. Di Pardo y E. L. Menéndez (Ms. 1981) se concluye que no existe actualmente acuerdo teórico más allá de los operativos, y que aun aquella categoría diagnóstica que pretende ser más precisa, el síndrome de dependencia, aparece inconsistente en los mismos que la proponen. Como dice el mismo G. Edwards: "Carecemos de un modelo bien trabajado y válido que explique el alcoholismon (198p; 308).

M. Blaxter ha realizado una notable investigación que demuestra la confusión dominante respecto del diagnóstico de alcoholismo. Como es sabido, todo diagnóstico supone una intención clasificatoria que la práctica médica realiza a partir de signos y síntomas. En gran medida los diagnósticos son listados de síntomas y signos organizados de tal manera que permitan dar terapia. En consecuencia, para varios investigadores del problema del diagnóstico médico, éste constituye básicamente una prescripción. Ahora bien, ¿qué ocurre cuando la acción prescriptiva es impracticable, ineficaz, o está fuera del marco de referencia médica? Según Blaxter, esta situación puede conducir a que: I) si la acción prescriptiva es imposible o ineficaz, se tenderá a no diagnosticar; II) si la acción puede ser realizada por otras personas, el diagnóstico será evitado o usado en circunstancias donde hay estructuras para la derivación formal a otro; III) si la acción no se considera propia de sus capacidades, el diagnóstico puede ser derivado a otra categoría médica más apropiada; IV) si los signos y síntomas de la enfermedad no son aquellos que le permitan sentirse competente para identificar y medir, entonces se tomarân en cuenta ciertos estereotipos relativamente burdos o idiosincráticos del síndrome o del paciente típico. La autora analizó este cuerpo de posibilidades a través de las altas de un año de hospitales no psiquiátricos de una región del Reino Unido. Aplicando la Clasificación Internacional de Enfermedades encontró que la categoría residual «otros problemasn comprendía más de la mitad de los diagnósticos de alcoholismo. Si a esto se agrega que la codificación de alcoholismo como enfermedad es muy limitada, ya que «un diagnóstico sobre alcoholismo como primera causa es improbable», nos encontramos con que la captación diagnóstica es míni- 
ma. Blaxter encontró que cuando el médico diagnosticaba alcoholismo era porque había intoxicación alcohólica o porque ya existía un diagnóstico psiquiátrico previo, traído por el propio paciente o dado por otro profesional. Además, su investigación evidenció la evitación del tratamiento de este tipo de paciente por parte de los médicos (M. Blaxter, 1978).

Esta situación se da en México con una intensidad aún mayor, dado que si bien el problema es reconocido a nivel formal, a nivel de los hechos las acciones son pocas. Una de las principales autoridades mexicanas en alcoholismo desde la perspectiva de la Salud Pública señala: "Contemplado como problema general, lo que se hace en México no es pobre, sino paupérrimo" (Velazco Fernández, 1977:36). A su vez uno de los más destacados clínicos, para muchos el más destacado especialista mexicano actual, el doctor J. A. Elizondo, indica: «Desafortunadamente, debemos admitir que se ha logrado muy poco en el tratamiento de este tipo de enfermos, ya que la mayoría de los miembros de la profesión médica, con algunas excepciones, no han enfocado constructivamente el problema del alcoholismo. Han sido indebidamente lentos en reconocer el alcoholismo como una enfermedad y, en su práctica, han tendido a descartar a pacientes alcohólicos como desahuciados a lo sumo desagradables o no remunerables» $(1977: 45)$.

El problema del diagnóstico y tratamiento médico del alcoholismo supone tanto el «desinterés» por una parte de la práctica médica, como también éxitos muy limitados de dicha práctica sobre el problema. Para muchos autores, es esto último lo que determina el citado «desinterés».

En la última revisión del problema por expertos de la OMS, se dice: "Aunque muchos de estos servicios terapéuticos han logrado demostrar que aproximadamente una tercera parte de sus pacientes se conservan abstemios o por lo menos consumen cantidades notablemente menores de alcohol durante un año o dos después del tratamiento, una serie de ensayos clínicos en que se han comparado regímenes de diversos tipos han puesto en duda el significado de estos resultados aparentemente satisfactorios. Algunos ensayos adecuadamente organizados, en que la selección de los sujetos se ha hecho al azar, han demostrado, por ejemplo, que el índice de éxito en términos de abstinencia o reducción del consumo puede ser tan favorable después de sólo unas semanas de hospitalización como después de varios meses, y que el tratamiento en los ambulatorios puede ser tan eficaz como el de los pacientes internos. Un ensayo indica, incluso, que la simple previsión de consejos inequívocos para dejar de beber, en circunstancias adecuadas, proporciona resultados tan positivos como un conjunto de medidas terapéuticas laboriosas y costosas». Conjuntamente se han acumulado pruebas de que personas que alguna vez en su vida tuvieron síndrome de dependencia pudieron luego dejar de beber completamente o adoptar una forma normal socialmente aceptada «... después de haber recibido un breve tratamiento formal, $\mathbf{y}$ aun ninguno, tanto en el terreno médico como fuera de él» (OMS, 1980:53-54). $\mathrm{El}$ informe concluye que estas experiencias han conducido a plantear formas cada vez más simples de tratamiento «... que quizá sólo consistan en poco más que impartir consejos firmes al sujeto para que deje de consumir alcohol o consuma menos, junto con el suministro de información acerca de las cor sencias del consumo irrestricto y continuo, la adopción de medidas estratégicas sencillas para reducirlo y la evaluación de los adelantos que logren» (OMS, 1980:54).

$\mathrm{Si}$ bien esto puede suponer un «desentendimienton del problema, lo que emerge con claridad es la abdicación del $\mathrm{MMH}$ para hacersé cargo coherentemente del problema. El tratamiento del alcoholismo constituye una historia, como dice Edwards, de técnicas desechadas unas tras otras hasta ir quedándonos con las más simples, menos costosas, y entre las cuales la más relevante parece ser Alcohólicos Anónimos (A.A.). Según J. Jaffe, la mayoría de los programas formales de tratamiento en EE.UU., Canadá y otros países capitalistas basan sus acciones en los grupos de A.A. Analizando uno de los principales programas que se aplican en la actualidad, el del Hospital Naval de Long Beach, señala que éste incluye prioritariamente consejeros ex-alcohólicos, encuentros grupales e integración a los programas de A.A.

Este es el modelo general más aceptado, el cual parte de la convicción de que es determinante la participación de la citada asociación de ayuda mutua. G. Edwards enumera los puntos que considera estratégicos para el actual tratamiento alcohólico: diferentes pacientes requieren diferentes tipos de ayuda; evaluación del paciente para determinar el tipo e intensidad del tratamiento; identificar las condiciones particulares y tratarlas; el momento de búsqueda de ayuda debe ser considerado como básico; los objetivos deben ser acordados, más que impuestos; el terapeuta debe tener una actitud positiva; la autodeterminación y autorresponsabilidad deben ser enfatizadas; deben darse recursos al paciente para poder asumir el tratamiento; debe ser impulsado el autocontrol; la esposa debe estar involucrada en todo el proceso; el tratamiento debe ser ambulatorio, salvo si exige internamiento, el tratamiento profesional debe ser mantenido a un nivel mínimo, de tal manera que permita al propio paciente manejarlo; la dimensión social es importante para el manejo con la realidad externa; la referencia a AA debe ser rutinaria cuando se elija un objetivo de abstinencia y el costo del tratamiento debe ser controlado para maximizar los beneficios. En esta enumeración no sólo se señala la participación de $\mathrm{AA}$, sino que en por lo menos siete ítems se recomienda el automanejo o la cogestión del problema por parte del paciente. 
Ahora bien, contra lo que se suele suponer, la estrategia tipo AA no procede de la década de los 30, sino de fines del siglo XIX, cuando varias instituciones de «ayuda mutua» se crean específicamente para dar solución a este problema en Suiza, EE.UU. y Francia, y luego en otros países europeos. Tampoco esta estrategia está limitada a los países capitalistas metropolitanos y dependientes, sino que ha tenido un notable desarrollo en varios paises de «socialismo real». Asi, en la zona croata se han desarrollado los clubes para alcohólicos. «Muchos de estos clubes están ligados a planes específicos de trabajo y su objetivo principal es el de mantener la sobriedad entre sus miembros mediante la ayuda mutua, aunque también tienen un rol preventivo en la comunidad. Una decisión tomada en 1970 por el Parlamento de la República Socialista de Croacia sugirió que, con la ayuda de las fuerzas sociales de la comunidad, los miembros del Club podrían trabajar en la esfera del control del alcoholismo y en la rehabilitación de los alcohólicos que hubieran recibido tratamiento, ayudando también a conseguirles trabajon (J. Moser, 1979:165).

Señalemos además que en algunos países ha sido sólo este tipo de estrategia el que ha sido aceptado por los trabajadores para enfrentar el problema del alcoholismo dentro de la esfera laboral. Como es sabido, los trabajadores han ofrecido siempre una fuerte resistencia a toda política empresarial o estatal dirigida contra esta problemática.

Este reconocimiento "médico" se traduce, por supuesto, en una creciente visibilidad social de AA por parte de todos los conjuntos sociales. Las investigaciones realizadas en casi todos los países donde funcionan los AA o sus equivalentes indican que este tipo de institución es el reconocido como más idóneo y eficaz por la población. En el caso de México, el estudio dirigido por G. Calderón y otros indicó que mientras el $83 \%$ de los entrevistados recomendarian $\mathrm{AA}$ a un amigo o pariente, sólo un $49 \%$ recomendaría un médico y un $33 \%$ a la Iglesia.

Como no viene al caso discutir aquí el origen y la ideología de esta institución, lo que debemos reconocer es: que se basa en la autoayuda; que constituye la alternativa más eficaz reconocida por la propia población; que esto opera más relevantemente ante el fracaso y/o falta de interés del $\mathrm{MMH}$; que habiendo sido inicialmente marginada por el sistema oficial de salud, tiende a ser no sólo reconocida, sino institucionalizada por el mismo; que en América Latina opera no sólo en los estratos medios, sino sobre todo en los estratos bajos; que en su proceso de institucionalización puede captarse el proceso de cura y control; que aparentemente se constituye tanto en paises capitalistas como de socialismo real.

A partir de lo descrito nos planteamos, no el análisis de la organización, ideología y estrategias de AA (esto es materia de otro trabajo), sino discutir los posibles fundamentos teóricos e ideológicos de las formas de autoayuda, sean autogestionarias o no.

3. De nuestro análisis se desprende que la «solución» actual a la problemática del alcoholismo está basada en un grupo de ayuda mutua: Alcohólicos Anónimos. En general y desde una perspectiva frecuentemente radical, se acepta que este tipo de instituciones son fácilmente captadas y utilizadas por los sistemas dominantes. Sin negar esta aseveración consideramos que la mayoría de estas afirmaciones son exclusivamente ideológicas y no se asientan ni en elaboraciones teórico-ideológicas y mucho menos en análisis específicos. Al sostener esto no queremos afirmar lo contrario, sino justamente proponer realmente el análisis de esta problemática.

Lo primero a considerar es justamente en qué consiste estructuralmente la autoayuda. Todas las tendencias plantean elementos comunes: reciprocidad, socialización primaria no satisfecha por otras relaciones, determinados grados de control en las acciones comunes. Los dos primeros elementos son comunes a toda sociedad; así lo reconoce la producción antropológica en relación a las sociedades «primitivas» y según A. Gouldner: "Sospecho que la norma de la reciprocidad es un elemento de la cultura no menos universal e importante que el tabú del incesto...» (1979:231) y agrega: «Específicamente, sostengo que la norma de la reciprocidad, en su forma universal, plantea dos exigencias mínimas relacionadas entre sí: 1) la gente debe ayudar a quien le ha ayudado, y 2) la gente no debe perjudicar a quien le ha ayudadon (id.: 232). Esta concepción teórica, que por otra parte ha sido empleada por Marx, Mauss, Malinowski, Levi-Strauss y Homans, ha sido tambiné codificada por la práctica cotidiana: «... la creencia existencial en la reciprocidad dice algo por el estilo de lo siguiente: «la gente habitualmente ayuda a quien lo ayuda». Análogamente la norma de la reciprocidad prescribe que la gente debe ayudar a quien la ayuda y, por tanto, aquellos a quienes hemos ayudado tienen la obligación de ayudarnos» (id.: 236)

Ahora bien, la reciprocidad no implica incondicionalidad ni que se intercambie lo mismo, sino que la reciprocidad puede no cumplirse o bien pueden intercambiarse diferentes elementos siempre y cuando tengan equivalencia, ya que «... la norma de la reciprocidad estipula que la cantidad de retribución que ha de darse es "aproximadamente equivalente" a lo que se ha recibidon (íd.: 233).

Según algunos antropólogos, el mantenimiento de una reciprocidad simétrica, típica de la mayoría de las sociedades «primitivas», aseguraría su 
igualitarismo, así como la inexistencia no sólo de una división en explotados y explotadores, sino entre dominados y dominadores. $\mathrm{Al}$ margen de si concordamos con él, ha sido P. Clastres quien más ha tratado de enfatizar estas condiciones como punto de partida, por lo menos metodológico, del análisis de las actuales condiciones de dominación y explotación.

Pero la reciprocidad puede darse a partir de posiciones qué implican asimetría, en las cuales de hecho tiende a desaparecer el otro elemento: la ayuda mutua. En consecuencia, la reciprocidad sólo implica ayuda mutua cuando opera entre iguales o por lo menos entre equivalentes. Por lo tanto, reciprocidad y ayuda mutua establecen un nivel horizontal de relaciones que no está implicado necesariamente en la reciprocidad por sí sola. Mientras que en las sociedades "primitivas" se dan ambas relaciones, pues en ellas basan gran parte de su producción y reproducción, en las sociedades estratificadas los mecanismos de reciprocidad funcionan tanto a nivel horizontal como vertical, mientras que los mecanismos de ayuda mutua emergen en situaciones que aparecen frecuentemente como «marginales». Esta «marginalidad» cobra dos formas básicas: $b$ ) una marginalidad autónoma y no manipulada; b) una marginalidad aparentemente autónoma, que es potenciada y manejada por la sociedad dominante. Esta última forma ha sido la más frecuentemente nalizada, una de cuyas variantes más notorias ha sido justamente la "comunidad primitiva", que la situación colonial ha construido o reconstruido o reforzado, pero manteniendo los mecanismos básicos de dominación y explotación (E. L. Menéndez, 1969).

Las sociedades basadas en la reciprocidad y la autoayuda serían las únicas sociedades no escindidas que habria producido el desarrollo humano. Como dice P. Clastres, «como sociedades completas, acabadas, adultas y no ya como embriones infrapolíticos, las sociedades primitivas carecen de Estado porque se niegan a ello, porque rechazan la división del cuerpo social en dominadores y dominados. La política de los salvajes se opone constantemente a la aparición de un órgano de poder separado, impide el encuentro siempre fatal entre la institución de la jefatura y el ejercicio del poder. En la sociedad primitiva no hay órgano de poder separado porque el poder no está separado de la sociedad, porque es ella quien lo detenta como totalidad, con vistas a mantener su ser indiviso, de conjurar la aparición en su seno de la desigualdad entre señores y súbditos, entre el jefe y la tribu» (1981:115).

Pero como ya se señaló, estas sociedades han concluido convertidas en "sujetos» aparentemente autónomos, pero de hecho dominados. El modelo clásico ha sido el del gobierno indirecto, que por otra parte no impidió cuando fue necesario el mantenimiento interno de la reciprocidad y la autoayuda en casi todas las dimensiones, incluida la de salud, pero exceptuando el poder real hacia el exterior.

Ahora bien, el análisis de la reciprocidad y de la autoayuda nos lleva no sólo a plantearnos el problema de la autoatención en salud, sino más ampliamente a tratar el problema del poder y la posibilidad o no de la reciprocidad simétrica y la autoayuda, o si se prefiere de la posibilidad de la autogestión colectiva en salud.

Las sociedades "primitivas»", al igual que los grupos obreros de ayuda mutua del siglo xıx, al igual que grupos de autoatención en salud actuales, han concluido apropiados por el sistema dominante. Este «destino funesto" ¿es producto de una inevitabilidad estructural, o constituye un riesgo histórico? Como ya se señaló, la mayoría de los autores radicales pretenden que constituye una inevitabilidad. Lo que vamos a tratar de analizar son las condiciones teóricas de la misma. En principio, subrayemos que es en las situaciones estratificadas donde emerge conscientemente la exigencia del control autogestionario.

La producción empírica y teórica sobre esta problemática permitiría sintetizar una serie de posibles acuerdos: a) reconocer como estructurales en toda sociedad "primitiva» los mecanismos de reciprocidad simétrica y autoayuda, y la autoatención en salud como parte de los mismos; b) reconocer la importancia estructural de la dimensión salud/enfermedad en toda sociedad; c) reconocer en toda sociedad, incluso en las estratificadas, el mantenimiento de formas que implican una autonomía relativa sobre la salud por parte de los conjuntos sociales; $d$ ) reconocer que en nuestras sociedades los conjuntos no tienen capacidad de control sobre sus procesos cotidianos globales, tendiendo sólo a mantener un control fragmentado sobre los mismos; e) esta pérdida de control sobre la cotidianidad se agudiza a medida que nuestras sociedades se planifican concentracionaria y burocráticamente, intentando reducir los conjuntos a la privaticidad de los microgrupos; $f$ ) este proceso no es unidimensional sino conflictivo y contradictorio, y si bien tiende a la institucionalización de las características señaladas ello no supone necesariamente la subordinación inevitable o, si se prefiere, estructural.

La emergencia de esta problemática debe ser relacionada con el desarrollo de la revolución industrial, y la constitución del proletariado en los países de capitalismo temprano. La problemática explotación/dominación/alienación puede ser sintetizada a través de la pérdida de control creciente sobre todas las áreas de la cotidianidad, incluido de manera relevante el trabajo, aunque sin reducir a éste la dinámica del proceso global. El proceso productivo constituye el eje de estas transformaciones, en la medida 
que en él se establece la ruptura más significativa respecto del control de la cotidianidad, incluidos los medios de producción. De allí que la tendencia del capitalismo supondrá «... un esfuerzo patronal para disolver el proceso del trabapo como un proceso conducido por el obrero y reconstituirlo como un proceso dirigido por la administración patronal» $(\mathrm{H}$. Braverman 1975:201). Pero esta focalización del proceso capitalista caracterizada por el énfasis continuo en la construcción de formas internalizadas de trabajo repercutirá reorganizativamente en todas las esferas de la vida cotidiana. Así, por ejemplo, la producción de cerveza, alimento básico del campesinado y proletariado británicos, dejará de ser un producto de elaboración doméstica para convertirse en un producto fabril de consumo externo a la unidad familiar.

Este proceso, así como las respuestas políticas, sociales e ideológicas, teorizadas o no, se desarrollarán en un lapso de 200 años a través de una serie de propuestas que podemos ordenar metodológicamente en torno a cuatro situaciones diferenciadas, aunque articuladas en el proceso capitalista/socialista: $a$ ) Desde fines del siglo xvm hasta el desarrollo de la etapa imperialista: las principales propuestas emergieron del socialismo utópico, del marxismo, del anarquismo, del populismo ruso, del cooperativismo y del mutualismo; $b$ ) desde la etapa imperialista hasta el inicio de las economías planificadas socialistas y capitalistas: el participacionismo socialdemócrata y el «consejismo" caracterizan esta situación; $c$ ) desde el desarrollo de las economías planificadas hasta mediados de 1950: este período está dominado por la recuperación de las unidades grupales y comunales por parte de corrientes académicas, así como por la recuperación de estas unidades en la situación colonial; ${ }^{1} d$ ) desde mediados de los 50 hasta la actualidad: irrupción de corrientes consejistas en países capitalistas y socialistas, así como de tendencias comunalistas, de cogestión incluidas tendencias que se plantean estas alternativas en el área de la salud.

3.1. La primera situación está dominada en términos teóricos: por la "experiencia» de la Comuna de 1871; en términos políticos: por las concepciones marxistas y anarquistas; y en términos sociales: por la implantación de las comunas socialistas y las diferentes formas de cooperativas en Europa y América.

$\mathrm{Si}$ bien casi todas estas tendencias buscan la transformación de la sociedad, divergen en cuanto a los medios y formas organizativas a implementar. No obstante todas aspirarían a sociedades basadas en la cooperación simétrica. Frente a un proceso capitalista que generaba profundas reorganizaciones en la cotidianeidad se darán propuestas alternativas de tipo eminentemente defensivo (reconstrucción de los mecanismos de ayuda mutua), ofen- sivas (La Comuna) o marginales al sistema (las comunidades socialistas). En todas estas respuestas no sólo se plantean la cooperación y la autoayuda, sino que se cuestiona al estado pjauperizador, y se plantean grados necesarios de autocontrol de la spropias actividades.

Que esta propuesta no se haya cumplido, que la misma desapareciera de algunas corrientes, no niega que se hubiere planteado. Lo que debemos es analizar por qué tanto en las corrientes comunitarias se pierde la autonomía, como en las tendencias socialdemócratas y ulteriormente «comunistas» se pierde la concepción del control obrero.

En las tendencias citadas pueden detectarse los siguientes rasgos estructurales: radical-reformista/político-cultural/general-microsocial/revolución (toma del poder)-proceso. Los primeros términos corresponderían al movimiento «comunista» que ha concluido en un poder de tipo burocrático; los segundos al movimiento "comunitario" que ha concluido siendo absorbido o destruido. Por supuesto que la cuestión no está en plantear tipologías, que nunca coinciden totalmente con la realidad, sino en extraer conclusiones de las mismas y de los procesos. Una primera conclusión casi obvia es que ni los contenidos de reciprocidad y control simétrico surgen mecánica ni espontáneamente de la toma del poder, ni los mecanismos de reciprocidad y autoayuda generan espontáneamente las transformaciones.

En general, las tendencias políticas radicales han cuestionado las tendencias cooperativas/comunitarias. Según P. Mattick «El movimiento cooperativo fue fácilmente integrado en el sistema capitalista $y$, de hecho, fue también un elemento del desarrollo capitalista. Incluso en la teoría económica burguesa era considerado un instrumento de conservadurismo social (las cooperativas de consumo) en la medida que estimulaba la tendencia al ahorro de los estratos inferiores de la sociedad, incrementaba las actividades económicas por medio de asociaciones de crédito, perfeccionaba la agricultura por medio de cooperativas de producción y organizaciones de comercialización, y también en la medida en que desviaba la atención de la clase obrera de la esfera de la producción hacia el consumo» (1977:63-64). Pero esto también ha sido reconocido por los mismos sectores reformistas, dados los radicales cambios de algunas de las principales organizaciones de este tipo. Así la Alianza Cooperativa Internacional, desde fines del siglo xıx, deja de lado la exigencia de «participación» a sus trabajadores y tiende a reconocerlos directamente como asalariados.

De hecho la exigencia de «participación" fue desapareciendo de las concepciones cooperativistas, aun cuando en sus congresos recurrentemente se vieran obligados a ponderarla. En 1942 dos sociólogos profesionales británicos, simpatizantes del cooperativismo, señalaban que los dos principales 
rasgos negativos de este movimiento eran: $« a$ ) el hecho de que se esfumen los caracteres por los cuales una empresa cooperativa se distingue de una empresa comercial, en particular por la adopción de las mismas fórmulas de éxito; $b$ ) el hecho de que entre los dirigentes disminuye la sensibilidad hacia las necesidades del conjunto de los consumidores” (C. Saunders y F. Peers: citados por E. Infield 1959:174).

Ahora bien, esta pérdida de los objetivos de reciprocidad, autoayuda y control colectivo es contrastada por otros con la existencia de una desviación similar en los socialismos burocráticos. El problema a resolver es si son incompatibles este tipo de relaciones con el mantenimiento del poder.

«A. E. Bestar, el historiador más agudo del movimiento comunitario, ha señalado que en todas estas comunidades existía un tema unificador, la creencia de que una pequeña comunidad experimental podía utilizarse como medio de una reforma radical de la sociedad» (K. Melville, 1980:37) y agrega Melville que estas comunidades buscaron durante el siglo xix cambiar las condiciones impuestas por el capitalismo planteándose un enfoque radical: «Pero la perspectiva de una reforma radical a través de la revolución violenta era aún más oscura y temible después de las experiencias revolucionarias europeas entre 1870 y 1815 . La única alternativa a la revolución era la formación de unas comunidades deliberadas que encararan ideas radicalmente nuevas» (1980:37.38). Como es sabido la mayoría de estas comunas se desintegraron o se convirtieron en «sociedades» capitalistas. Este tipo de transformación también operó en las organizaciones de «ayuda mutua». Si bien sirvieron inicialmente para enfrentar los problemas de supervivencia (sociedades del valle del Po desde fines del siglo xIX) no configuraron una alternativa.

Este proceso ¿supone negar la validez de estas tendencias, o las mismas deben ser analizadas como parte complementaria de un sistema de opciones dentro de los cuales cumplen funciones necesarias?

$\mathrm{Si}$ bien Marx ha criticado el movimiento cooperativo, también ha reconocido sus aportes: «...las fábricas cooperativas de los obreros mismos, son, dentro de la forma tradicional, la primera brecha abierta en ella, a pesar de que, donde quiera que existen, su organización efectiva presenta naturalmente, y no puede menos de presentar, todos los defectos del sistema existente. Pero dentro de estas fábricas aparece abolido el antagonismo entre el capital y el trabajo, aunque por el momento solamente bajo una forma en que los obreros asociados son sus propios capitalistas, es decir, emplean los medios de producción para valorizar su propio trabajon (citado por Y. Bourdet, 1977:69), y agrega Marx en 1866: «reconocemos al movimiento cooperativo como una de las fuerzas transformadoras de la sociedad presente, ba- sada en el antagonismo de las clases. Su gran mérito consiste en demostrar prácticamente que el sistema actual de subordinación del trabajo al capital, despótico y pauperizador, puede ser suplantado por el sistema republicano de la asociación de los productores libres e iguales" (Id.: 70) para ocncluir «El sistema cooperativo restringido a las formas minúsculas surgidas de los esfuerzos "individuales" de los esclavos asalariados, es impotente para transformar por sí misma a la sociedad capitalista. Para convertir la producción social en un amplio y armonioso sistema de trabajo cooperativo, son indispensables cambios generales. Esos cambios nunca serán obtenidos sin el empleo de las fuerzas organizadas de la sociedad. Por lo tanto el poder del Estado, arrancado de las manos de los capitalistas y de los propietarios de la tierra debe ser manejado por los productores mismos» (Id.:72). Y. Bourdet comentando el informe de Marx a la AIT, el programa de Ghota y el trabajo sobre la Comuna concluye: «Me parece que todo debe estar bien claro ahora: las cooperativas autodirigidas son las primeras realizaciones concretas de la utopía de una sociedad sin clases. Pero esas cooperativas no pueden verdaderamente desarrollarse, conforme a su esencia, mientras subsista un estado central, dominador y también protector. Es otra organización igualitaria y cooperativa de la sociedad en su conjunto la que constituirá la revolución» (1977:72).

Por supuesto que de Marx podrían extraerse citas distintas y que apunten a fundar otra interpretación; pero aquí lo que nos importa recuperar, por encima de las lecturas bíblicas, es la ponderación del proceso de cooperación autónoma y controlado como experiencia fundacional de una nueva organización social.

Ahora bien, los procesos generados por las diferentes tendencias señaladas operan dentro de un campo social orientado básicamente por el desarrollo capitalista, que si bien tiende a la privatización, a la individualización, etc., también trata de apropiarse de las formas comunales, corporadas, etcétera, cuando cumplen funciones para la producción y reproducción. Esto lo que indica es un proceso expansivo y potencialmente conflictivo y no la negatividad intrínseca de las tendencias analizadas.

El capitalismo individualiza, tiende a la privatización pero socializadamente. Esta obviedad debe ser subrayada. M. Foucault lo ha puesto de relieve en el campo de la práctica médica: "Sostengo la hipótesis de que con el capitalismo no se pasó de una medicina colectiva a una medicina privada, sino precisamente lo contrario; el capitalismo que se desenvuelve a fines del siglo xvII y comienzos del siglo xIX socializó un primer objeto que fue el cuerpo, en función de la fuerza productiva de la fuerza laboral» (1977:5) y describe los cuatro grandes procesos a través de los cuales la 
práctica médica deviene «social» durante dicho período: a) La aparición de una autoridad médica, que puede tomar decisiones de tipo social y político; b) La aparición de un campo de intervención de la medicina distinto de las enfermedades: el aire, el agua, las construcciones, los terrenos, los desagües, etc.; c) El desarrollo del hospital como aparato de medicalización colectiva y $d$ ) La introducción de mecanismos de administración médica. La aparente paradoja es que se va instituyendo una medicina de control al mismo tiempo que la sociedad enfatiza la necesidad de desarrollar mecanismos de responsabilidad individual: «La legislación inglesa tiende cada vez más, en el curso de la segunda mitad del siglo xvıI a favorecer la iniciativa privada en el dominio de la asistencia. Se organizan especies de grupos de seguridad, se favorecen las acciones de socorro... Puede comprenderse que, en las condiciones nuevas de fines del siglo xvm, haya sido aprobada una ley en 1793 para «el fomento y el sostén de las sociedades amistosas»... El texto de la ley precisa que pueden esperarse de esas instituciones «efectos muy benéficos, ayudando a la dicha de los individuos y haciendo disminuir al mismo tiempo el fardo de las cargas públicas» (M. Foucault, 1979: II: 192-193).

El sistema capitalista se desarrolla conflictivamente entre la delegación y el control, pero necesitando de hecho imponer un control estructural, es decir, que funcione «naturalmente» a través de las instituciones internalizadas. Es este control el que, cuando se hace «visible», conduce a sectores liberales a cuestionarios. Así una persona escribía al Times de Londres en 1854: "Preferimos aceptar el riesgo de atrapar el cólera o la peste, antes de ser brutalizados y obligados por el Estado». Como dice J. Attali: «En todas partes el capitalismo liberal produce, por tanto, un estado a la vez organizador del mercado y asegurador contra las consecuencias de su juego, y hay coincidencia entre la aparición de los primeros Estados del orden nuevo y la generalización del seguro público» (1981:181).

Dentro de este proceso conflictivo la salud aparece como una importante dimensión de la autoayuda y de la ayuda mutua, aun cuando el estado tienda a hacerse cargo de estas áreas, frecuentemente por la presión del proletariado y otras veces como expansión de su propio proceso de cura y control.

¿Constituye la dimensión salud un eje de acción antiestatal y anticapitalista en este período? No, la dimensión salud/enfermedad formará parte de un grupo de acciones reivindicativas que utilizan los mecanismos de autoayuda y reciprocidad y que aparecen ligadas tanto a las tendencias anarquistas, cooperativistas, como socialdemócratas.
3.2. La segunda situación corresponde al período de institucionalización de la gestión científica del trabajo, a la hegemonía socialdemócrata y a la primera etapa consejista, incluida la inicial gestión de los soviets en Rusia.

Tanto la evolución participacionista de la socialdemocracia, como la radicalización del consejismo y del anarcosindicalismo deben ser estrechamente relacionados con la institucionalización del taylorismo. Como señala Braverman: «Es en la época de la revolución científico-técnica cuando el patrón se plantea el problema de dominar el proceso como un todo y controlar cada uno de los elementos sin excepción... Y es la evolución científico-técnica la que proporciona los medios para la realización parcial de este ideal teóricon (1975:202).

Taylor, Fayol y la teoría de la burocracia codificada por M. Weber constituyen los límites organizativos dentro de los cuales se busca la máxima racionalidad y productividad, excluyendo la participación organizada autónomamente de los trabajadores: «Las conclusiones a las que Taylor llegó después del bautismo de fuego que recibió en la lucha de Midvale pueden ser resumidas como sigue: los obreros que están controlados tan sólo por órdenes y disciplinas generales, no lo están adecuadamente, debido a que mantienen su iniciativa en los procesos reales del trabajo. Mientras controlen el proceso mismo del trabajo, ellos impedirán los esfuerzos para realizar el máximo potencial inherente en su fuerza de trabajo. Para cambiar esta situación el control sobre el proceso de trabajo debe pasar a las manos de la gerencia, no sólo en un sentido formal sino a través del control y el dictado de cada paso del proceso, incluyendo su modo de ejecución” (H. Braverman, 1975:124). El desarrollo capitalista exige tanto por razones de productividad, como por eficacia del control (por lo menos en esta etapa) la erradicación de toda posibilidad de autonomía obrera sobre el proceso productivo y la centralización unipersonal del mando.

Tanto la socialdemocracia, como el «comunismo* en el poder iban a asumir estos postulados capitalistas gerenciales. Los únicos grupos que en teoría y práctica cuestionaron esta orientación fueron los anarcosindicalistas y los consejistas. Si bien hubo fuertes divergencias en las prácticas y tendencias, los elementos comunes están constituidos por la autonomía y la exclusión de toda participación: «Afirmar que el aumento gradual del control obrero en el capitalismo es una posibilidad real significa sólo hacer el juego de la demagogia propagada por las clases dominantes para disimular su dominio de clase absoluto, a través de falsas reformas sociales disfrazadas en términos como cogestión, participación o codecisión. El control obrero excluye la colaboración de clases; no puede tomar parte en el sistema de produc- 
ción capitalista, sino que, en lugar de eso, lo destruye. En ninguna parte el socialismo o el control se hicieron realidad. Capitalismo de estado y socialismo de mercado o la combinación de ambos, continúan manteniendo a la clase obrera en la posición de trabajadores asalariados sin control efectivo sobre la producción y distribución» (P. Mattick, 1977:86-87).

Si bien esto fue escrito años después de la "situación» analizada, expresa ampliamente la concepción de los consejistas. Frente a esto las «alternativas» que obtuvieron el poder, es decir, la socialdemocracia y el «comunismon, iban a establecer sistemas de gestión muy poco diferenciados del capitalista y donde el control obrero, salvo el fulminante episodio de los soviets, iba a ser anulado y/o negado. La socialdemocracia condujo a transformar los consejos en «comunidad de empresan; Lenin, Trotsky y Stalin estuvieron acordes en implantar la administración "científica»: «Cualquiera que sea la visión que se tome de la industrialización soviética no se puede interpretar conscientemente su historia, incluso su primer y más revolucionario período como un intento de organizar los procesos de trabajo de madera fundamentalmente distinta a los del capitalismo» (H. Braverman, 1975:35)

Respecto de las tendencias analizadas, algunas condujeron a una suerte de indirect rule al revés: el rechazo de toda participación llevó a un sector a asumir de hecho la situación impuesta «encerrados en su propia organización»; casi replicando el modelo comunal en la situación colonial. Otros optaron por la llamada acción directa, otros por retornar a planteos exclusivamente sindicales, y un sector minoritario optó por permanecer en la alternativa consejista pero a nivel casi exclusivamente teórico. Como sabemos todos los intentos consejistas producidos hasta 1923 fueron destruidos.

3.3. La tercera situación supone la casi total desaparición de las tendencias consejistas salvo la experiencia española de 1934 (soviets asturianos) y sobre todo de 1936 . Este período se caracterizará por el desarrollo del «plan» así como por el incremento de la organización «científica» del trabajo en los países capitalistas y en la U.R.S.S. También se dará el descubrimiento de la espontaneidad y autonomía del grupo laboral por tendencias académicas y aplicadas básicamente en EE.UU. y por el «participacionismo» socialdemócrata. Podríamos decir que en esta situación se encapsulan los problemas ideológicos-políticos que suponían la autogestión, el control, la autoayuda, la reciprocidad y que los mismos son incipientemente rescatados por la práctica académica ligada al estudio de los problemas del trabajo.

Si tomamos el caso de la URSS observamos la institucionalización de un sistema de gestión laboral que es determinado por, y a su vez lo funda- menta, el desarrollo y mantenimiento de la burocracia como sector social que se justifica postulándose como director y controlador de la producción, excluyendo a los trabajadores de esas funciones. La producción teórica específica soviética al respecto expresa con absoluta claridad estas tendencias mucho más que los trabajos de orden «teórico» general.

La consulta de cualquier tratado o manual permite percibir esto. Analizando una obra de este tipo de extensa difusión en español, la de D. Gvishiani observamos que todo el problema de la organización del trabajo está centrado en la disciplina obrera, en la eficacia y en la productividad. Así para este autor la concepción leninista del mando unipersonal configura una solución dialéctica de la relación control obrero-centralismo democrático. Como sabemos este principio fue elaborado por y para la empresa capitalista, y de hecho la «solución» supone dar todo el poder al director de la empresa. De su obra surge que junto con el mando unipersonal, los otros elementos básicos de la gestión son la disciplina laboral (ps. 107) y los estímulos (ps. 108) y éstos referidos básicamente a la emulación.

Justamente, porque éstos son los principios básicos de la gestión «socialista» se puede aceptar «lo conveniente» de la gestión capitalista: «En este período (el de la NEP) se realizó un gran trabajo para estudiar la experiencia extranjero de vanguardia en materia de organización y gestión en las diversas organizaciones soviéticas. El Instituto Central del Trabajo, fundado a la sazón, se dedicaba a recoger y difundir las publicaciones extranjeras sobre problemas de organización del trabajo y de gestión (las obras de Taylor, Fayol, Emerson). Todo esto ayudó a superar el atraso de organización heredado de la Rusia zarista, a formar cuadros propios y elevar el nivel de gestión» (1973-112).

El mando unipersonal, el burocratismo, la concentración, la exclusión de la participación obrera en la gestión caracterizan todo este periodo, justamente cuando la propia práctica académica «burguesa» comienza a replanteárselo, y sobre todo cuando en 1936 en España las comunas rurales y las empresas industriales demuestran su capacidad autogestionaria, sin reducir la productividad ni en el medio campesino, ni en el fabril.

Con leves modificaciones la gestión «científica» dominará hasta la actualidad y ya no sólo en la URSS, sino en la mayoría de los países de "socialismo real». Gvishiani nos informa cómo durante los XXIII y XXIV congresos del PCUS se propusieron reformas a la organización del trabajo. En 1966 se pusieron en práctica contribuyendo al «...reforzamiento de los principios centralizados en la gestión, en plena consonancia con las leyes objetivas de desarrollo del modo socialista de producción» $(1973: 133 ; \mathrm{sic})$. Esta centralización supone «...la ampliación de los fundamentos democráticos de la 
administración y la más amplia incorporación de los trabajadores a la dirección de la producción» (1973:133).

¿Qué significa sobre todo el último punto? Esto queda claro en el siguiente párrafo: «Las direcciones principales del perfeccionamiento del sistema de gestión en la etapa actual de la construcción del comunismo, que ha determinado el XXIV Congreso del PCUS, consisten en primer lugar, en la elevación del nivel científico de la planificación; en segundo lugar, en el perfeccionamiento de la estructura orgánica de la gestión; en tercer lugar, en la aplicación consecuente del principio leninista de la responsabilidad individual, en el fortalecimiento de la disciplina en todos los eslabones del mecanismo de dirección de la economía nacional; en cuarto lugar en el reforzamiento del estímulo económico; en quinto lugar, en una participación más amplia de los trabajadores en la gestión y en sexto lugar en la amplia mecanización y automatización de la labor administrativa» (1973:136). Pero mientras que la mayoría de estos puntos y sobre todo el referido a la planificación son tratados ampliamente, en lo que respecta a la participación de los trabajadores sólo se refiere a «elevar el nivel de instrucción» y a enumerar formas de organización que o no dirigen nada o donde los trabajadores no deciden autónomamente: «Las formas de participación de las grandes masas en la gestión son muy diversas: desde la discusión por todo el pueblo de los planes de fomento de la economía nacional, hasta las asambleas de obreros y las conferencias de producción. En la gestión de la economía desempeñan un inmenso papel las organizaciones de base del partido, que encabezan y organizan la participación directa de los millones y millones de trabajadores en la solución de los problemas de elevar la eficacia de la producción, mejorar las condiciones de trabajo, racionalizar la producción, etc. Al lado de las organizaciones del partido, bajo su dirección, realizan un gran trabajo de organización en la producción los sindicatos de los trabajadores que disponn de considerables atribuciones en la solución de una serie de problemas de producción y organizan directamente la emulación socíalista, la iniciativa política de masas, etc.n (1973:154; sic).

$\mathrm{Si}$ bien desde fines del siglo xix, y sobre todo en tendencias alemanas $y$ norteamericanas, se plantea la discusión sobre los pequeños grupos y las relaciones primarias, será a partir de la década de los 20 , y desde diferentes prácticas académicas, cuando pasará a un primer plano la discusión sobre la naturaleza, funcionalidad, dinámica y racionalidad de los pequeños grupos, incluido el grupo laboral y la «pequeña comunidad». En general este "descubrimiento» de la espontaneidad microgrupal es coetáneo del desarrollo de las sociedadesp lanificadas y burocratizadas, del incremento en los ritmos productivos, del autoritarismo político y técnico.
Los pequeños grupos aparecen como aquellas unidades donde no sólo se podrían expresar las socialidades primarias, sino establecer por lo menos mínimos grados de control sobre las propias actividades. Estos grupos podrían desarrollar estas funciones "propias" aun en las sociedades más burocratizadas y dirigidas.

Tal vez los principales aportes teóricos y empíricos vinieron de los estudios realizados sobre los pequeños grupos de trabajo, en los cuales se descubre la funcionalidad del sabotaje, de la construcción de tiempos propios, de principios de reorganización por encima de los planificados a nivel empresario. Será en consecuencia de estos estudios desde donde saldrán las propuestas de reconocer márgenes de gestión obrera para aumentar así la productividad.

Los antropólogos a su vez «descubren», tras décadas de trabajo etnográfico, la racionalidad, la integración y la participación comunitaria. En muchos emerge la recuperación de sociedades homogéneas, en las cuales ponderan el nivel «moral» para oponerlo al nivel «técnico» de las sociedades estratificadas. De aquí ulteriormente se desarrollarán las propuestas de «desarrollo comunitarion ya sea basadas en la autoayuda o en la participación limitada.

$\mathrm{Al}$ margen de su instrumentación ulterior, estas concepciones plantean no sólo la importancia de los factores señalados, sino la necesidad procesal de la apropiación; si ésta no se da, de hecho las comunidades o grupos permanecerán dominadas o seguirán siendo «otras». Es la propia racionalidad la que debe cambiar en el proceso de apropiación.

En este trabajo dejamos de lado las consecuencias negativas de la dinámica microgrupal; las cuales, por otra parte, no debieran avalar una crítica unilateral de los descubrimientos señalados. La recuperación de la reciprocidad, de la ayuda mutua, de la espontaneidad, se realiza a partir del estudio académico de los "pequeños grupos» o de situaciones de sociedades colonizadas, muchas en el nivel tribal. No es nada casual que éste sea el período en que se funda Alcohólicos Anónimos, aun cuando su expansión corresponda a décadas ulteriores.

Que estos trabajos se hagan desde un plano académico, y no desde una perspectiva político-ideológica pone aún más en evidencia la negación que las fuerzas sociales "progresistas" del período tuvieron para aquellas dimensiones que cuestionaban su concepción estatalizada del socialismo. "La forma comunitaria, con sus resurgencias y sus metamorfosis, ése es el enemigo. Aquí, una vez más, no fue azar que Stalin, igual que Franco, hubiera querido liquidar las colectivizaciones de la revolución española. Lo que quiere imponer el Estado no son solamente las formas que se identifican dentro de 
su obediencia común a su legitimación única, sino también una fuerza que duplique todas las formas, de las más públicas a las más privadas, en el sentido deseado por él: es decir, la institucionalización» (R. Lourau, 1981:29).

Según Braverman, «durante la década pasada hubo una renovación de interés de la izquierda en los procesos del trabajo y en las formas en que son organizados. Esto puede ser atribuido a diversas causas... La bancarrota de la ideología comunista soviética había abierto el camino para un neomarxismo que intentó nuevos enfoques a los problemas del capitalismo y socialismo. En particular, las discusiones de la organización del trabajo en Cuba a mediados de la década de 1960 y la revolución cultural china fueron más allá de la distribución igualitaria de los productos del trabajo social y pusieron en un primer plano la idea de una revolución en la organización de la producción social» $(1975: 25)$ y agrega que a esto debe unirse la ola de radicalismo general surgida en el capitalismo funcionando en su «mejor» forma. Aquí « ...la insatisfacción se centraba no tanto en la incapacidad del capitalismo para proporcionar trabajo, sino más bien en el trabajo que proporcionaba» (id.: 25-26).

Además de éstos existen una serie de hechos generados a partir de la década de los 50 y que tienen tanta o mayor importancia en la recuperación de los objetivos señalados por Braverman: $a$ ) los brotes revolucionarios y consejistas en Yugoslavia, Alemania Democrática, Polonia, Checoslovaquia, Hungría; $b$ ) la problemática del «control» obrero en países con fuertes partidos comunistas sobre todo en Italia y en segundo lugar Francia y España, así como dentro de posiciones trostkistas; $c$ ) la creciente tendencia en países capitalistas, y asumida inclusive por la OIT, de la problemática de la «alienación» e insatisfacción laboral y la necesidad contradictoria de la empresa capitalista de delegar funciones de gestión en los trabajadores; d) las corrientes de rechazo a «la sociedad de consumo», sobre todo en los países de más alto desarrollo capitalista; $e$ ) el desarrollo de tendencias «regionalistas» con signo radical; $f$ ) el desarrollo de perspectivas académicas reformistas y radicales focalizadas en la autonomía y simetría, cuya área de mayor desarrollo se dio en el campo de la salud mental.

En la mayoría de estas tendencias el eje del cuestionamiento lo constituye la sociedad burocratizada y/o la burocracia y el control de los conjuntos autónomos. Esto no implica reconocer como de igual importancia a todos estos procesos, pero sí asumir que la orientación general intenta una superación radical de los sistemas de dominación vigentes.

Así, respecto de la experiencia autogestionaria, tal vez más cuestionada, la yugoslava, autores como Mandel, Bahro o Slansky la rescatan en términos comparativos: «... la introducción del sistema de autogestión de las empresas en Yugoslavia ha creado condiciones mucho más propias para el advenimiento de un verdadero poder de los trabajadores, que en cualquier otro país de los que han abolido el capitalismon (E. Mandel, 1974:41-42); y R. Bahro señala «las experiencias de Yugoslavia y China muestran que es posible, no sólo teóricamente, sino también práctico-políticamente contar con la realidad del Estado en las sociedades protosocialistas y utilizar el aparato estatal para la transformación revolucionaria sin hacer de la necesidad virtud (o desgracia que decía Engels) e inventarse una pseudodialéctica según la cual el «papel crecientex del Estado propugnado de congreso del partido a congreso del partido conduciría, naturalmente, a su extinción» (1979:279). No es nada raro entonces que cuando los polacos o los checoslavacos se plantearon alternativas recurrieran inicialmente al modelo yugoslavo. No es tampoco casual que en todos los casos la alternativa se plantee en períodos de aguda crisis social, económica y política. No fue tampoco inesperado que en todos los casos el sistema de dominación transija con varias demandas, excepto con la de autogestión real.

En su análisis del sistema soviético Bahro indica que la causalidad de la subalternidad y de la enajenación radica en una división del trabajo que se presenta generalmente como jerarquía de funciones del trabajo, y que la solución está en que las fuerzas sociales sean realmente las que dirijan: «Basta sólo con imaginarse esto, basta con reflexionar acerca de cómo se plantean entonces los problemas económicos para darse cuenta intuitivamente de que no se trata del plan o del mercado, del valor de uso o del valor de cambio, ni siquiera de la centralización o la descentralización. Con lo que en modo alguno se quiere decir que estos problemas desaparezcan: lo único que se evidencia es su importancia secundaria (1979:438-439).

Conjuntamente con los brotes «consejistas" en los países de «socialismo real». resurje en varios países capitalistas esta problemática, en particular en Italia. La cuestión del democratismo constituyó uno de los ejes del «morandismon, y de este grupo saldrían R. Panzierix y A. Negri, que identifican en diferentes períodos el desarrollo teórico y político del mismo. Si bien inicialmente la discusión se manifiesta a través de grupos marginales o marginalizados de los partidos políticos italianos, la misma será ulteriormente asumida inclusive por las direcciones sindicales. Las tendencias extraparlamentarias intentaron reiteradamente forzar experiencias de este tipo, que no sólo se centraron en la unidad fabril.

De hecho, la profundización de esta concepción llevó a algunos a proponer formas de cooperación autónoma. Esto ya plantea lo que «... con una terminología más reciente, comenzamos hoy a llamar procesos de autovalo- 
ración: procesos de reapropiación en propias manos de la fuerza proletaria... Recuperar toda esta serie de relaciones y dominarlas desde la perspectiva de la clase» (A. Negri, 1980:71-72). Una parte de estas corrientes enfatizan inclusive acciones cooperativas estigmatizadas, como puede ser el rechazo colectivo al trabajo.

Por encima del radicalismo de estas tendencias, lo que las mismas «descubren» es lo que la Antropología y Sociología «burguesas» venían planteando desde los años 20 y reiterando en investigaciones donde el tortuguismo, el sabotaje laboral, el robo, el no trabajo, etc., aparecían como formas normales de participar en el proceso productivo. Con signo ideológico distinto, lo que se encuentra es la cooperación de los trabajadores tanto en el trabajo como en el no-trabajo.

Durante las décadas de los cincuenta y sesenta se incrementaron las experiencias productivas en las cuales la propia dirección patronal acepta una alta autonomía obrera en el proceso productivo hasta límites no esperables dentro de la empresa capitalista. Esto se ha establecido sobre todo en trabajos donde la división técnica del mismo generaba frenos a una mayor productividad. Asumiendo que el control y la orientación de la producción por parte de la gerencia persisten, no pueden negarse no sólo las mejores condiciones de trabajo (sobre todo en lo referente a control y manejo del propio tiempo laboral y social), sino sobre todo en lo referente a la experiencia de autnomía y control parcial sobre el proceso productivo. Aquí se reitera lo señalado por Marx para las cooperativas de producción: el reconocimiento de la propia capacidad organizativa por parte de los trabajadores.

Toda una serie de movimientos y organizaciones surgidos en los años 60 plantearon como eje no tanto la práctica política o/y laboral, sino que colocaron en primer plano la autogestión en todos los niveles de la cotidianidad.

Por supuesto que esto debe ser relacionado con las nuevas condiciones de productividad y de inserción en el proceso laboral, pero también debe ser referido a las condiciones ideológicas y políticas que en los diversos sistemas se asientan en la planificación, la burocratización. La productividad como causa y consecuencia de estos procesos. Si bien este movimiento, en una de sus tendencias, apareció como desconectado de lo "político", no puede negarse por ello la influencia en los mismos de concepciones anarquistas y freudomarxistas que se expresaron por su oposición a las tendencias que en nombre de lo «político" trabajan consciente o/y conscientemente en favor de la cosificación del sujeto y de la "comunidad».

La burocratización tiende más que ninguna otra forma de dominación a negar «la diferencia»; las personas deben ser homogeneizadas como requisito de una mejor dirección y control. Burocratizar significa de hecho eli- minar a los «diferentes» tanto en términos políticos como sociales. De allí que estas tendencias asumieran en gran medida la "diferencia» como crítica negativa al sistema.

Asumir la «diferencia» supone no sólo reconocer ésta, sino también asumir los «errores", lo que no puede generar el estado burocrático en la medida que dicho no-reconocimiento (no desconocimiento) forma parte de su funcionamiento. Así, para P. Goodman, «... sólo una sociedad que posea la elasticidad propia de las comunidades descentralizadas puede absorber los inevitables fallos de los hombres. Pues allí donde existen grandes sistemas que funcionen a partir de un centro muscular único, los disparates de los custodios producirán una calamidad total» (Th. Roszak, 1981:216).

Coetáneamente la nueva teoría de la desviación, los situacionistas, los institucionalistas, la criminología crítica arribaban desde el marxismo, el anarquismo, el interaccionismo simbólico a concepciones similares. En todas ellas el eje era la impugnación total al «estilo de vida» dominante y la recuperación de la cotidianidad basada en nuevas relaciones sociales y no sólo de producción.

Al igual que la concepción leninista del militante a «tiempo completo", plantearon la concepción de impugnación también a tiempo completo y en todas las esferas de la propia actividad. «Cumplir con [los compromisos de impugnación] en las horas libres no procura la continuidad y universalidad. que exige un modo de vida según el cual pueda crecer y desarrollarse una madurez que puede incluir la actividad política, pero que además abrace muchas otras necesidades fundamentales: amor, familia, subsistencia, compañerismo. La acción política y organizativa sólo puede dar una modo de vida de entrega completa a un puñado de apparatchiks, dejando sin modelo de vida a toda una generación” (Th. Roszak, 1981:21). En consecuencia, para estas tendencias la impugnación no debe ser sólo al poder, sino al conjunto de las instituciones, junto con el proceso de cambio político, debe operar cotidianamente el cambio social e ideológico. El instrumento más idóneo serían las comunidades de autoayuda marginalizadas. Como es sabido, la mayoría de los intentos "comunales" fracasaron; pero también fracasaron todos los intentos consejistas. Es decir, que lo que ha fracasado hasta ahora son todos los intentos de cuestionar el orden institucional a partir del autocontrol real, ya sea a través de movimientos políticos y/o culturales.

Tanto la impugnación del «estilo de vida», como el reconocimientó de «la diferencia», como la solución a ambas a través de «nuevas relaciones sociales comunales y sociales», están ligados dialécticamente al desarrollo de las actividades terapéuticas en salud mental. 
Los principales hitos de este desarrollo son: $a$ ) el descubrimiento de las condiciones del funcionamiento del microgrupo; $b$ ) la derivación hacia la unidad "comunidad terapéutica»; c) el descubrimiento del poder y control terapéutico, aun en estas unidades; $d$ ) el intento de desarrollar grupos «naturales», o a partir de instituciones dadas de grupos realmente simétricos y «democráticos»; $e$ ) la negación de la «diferencia» como expresión «negativa»; su referencia a la desviación; ff) la disolución de la acción terapéutica, ya sea a través de la cogestión o de la autogestión.

En este desarrollo intervienen desde Mayo y Rogers hasta Lourau y Guattari, pasando por Laing y Basaglia. Los ejes constantes de todas estas tendencias son el grupo/comunidad y la autogestión/autoayuda. Para unos estos factores sólo expresan un nuevo campo de impugnación; para otros constituyen básicamente un medio terapéutico; para otros ambas cosas a la vez. Así, «el objetivo común de las nuevas terapéuticas es crear situaciones sociales, por lo general comprendiendo grupos de personas, en las cuales pueden relacionarse entre sí más honestamente en formas que normalmente no son permitidas. Al hacerlo, y no romper las barreras de la represión, resultan capacitadas para experimentar y expresar sentimientos y emociones genuinas y comienzan a explorar su verdadero potencial en relaciones más abiertas y fructíferas» (N. Heather, 1978:118). Según R. Speck, en el estudio intensivo de las «nuevas comunidades»: "Hemos observado reiteradamente que en los pads se trata con tolerancia y consideración a los jóvenes que padecen graves trastornos emocionales o que son psicóticos. Muchas veces, éstos son jóvenes a los que se recoge mientras andan vagando por la calle, y que no han tenido contacto previo con los miembros del pad. La forma en que los miembros del pad toleran la conducta anómala y aceptan las percepciones desusadas ha servido para sedar a muchos jóvenes alterados. Existen sólidos testimonios clínicos de que el apoyo y la comprensión de la red de pared pueden ser más beneficiosos para algunos adolescentes perturbados que el encierro en un hospital psiquiátrico, por muy idóneos y bienintencionados que sean sus profesionales. Grupos comunitarios como los de Kingsley Hall y The Arbor en Londres, y Number Nine en New Haven utilizan estos mismos métodos de la red de pared para tratar a individuos y grupos sociales» (1973:31).

En estos grupos no sólo se pondera «el efecto de red», la democratización de las relaciones terapéuticas, sino también la disolución del rol profesional del terapéutica. Múltiples investigaciones han demostrado la eficacia terapéutica de no profesionales tanto en la práctica médica general, como en la psiquiátrica. El Centro Comunitario de Salud Mental de la Universidad de Temple preparó 18 personas de la localidad, algunas sin preparación escolar secundaria, para atender enfermos mentales; trabajando sobre 250 pacientes redujeron la hospitalización en un $50 \%$ : «H. Strup comparó los resultados de la asistencia psiquiátrica dada a estudiantes por 12 terapeutas experimentados del personal universitario y 7 profesores de la Universidad, los cuales fueron seleccionados porque simpatizaban con los estudiantes y eran queridos por éstos. Los pacientes fueron todos estudiantes con problemas de timidez, introversión y que estaban ansiosos y deprimidos ... A los profesores se les pidió que se reunieran con los estudiantes y que hicieran lo que les pareciera natural para ayudarlos ... Los pacientes fueron evaluados al empezar la terapia, al terminarla y un año después. Los resultados fueron en general los mismos para los terapeutas entrenados y no entrenados» (M. Gross, 1978:75).

Concepciones y procedimientos similares, aunque ligados explícitamente a proyectos ideológico-políticos, se dan en tendencias italianas, francesas y también norteamericanas y latinoamericanas. (Ver E. L. Menéndez, 1979).

Todas estas tendencias han sido denunciadas como posibles de ser instrumentadas por la sociedad dominante, y esto de muy diversas maneras. Varias de las críticas son similares a las generadas para las orientaciones y prácticas basadas en los pequeños grupos; otras críticas apuntan a señalar el proceso de reinstitucionalización permanente, aun en tendencias inicialmente cuestionadoras: «En ciertos sectores en los que la psiquiatría daba especialmente pruebas de su incompetencia en hacer frente a problemas nuevos, en que no existian ni tradiciones, ni técnicas probadas, ni instituciones estructuradas, unos profanos, extraños a las profesiones médicas, han tomado directamente a su cargo los desafíos: free clinics para los jóvenes drop out, comunidades terapéuticas para los toxicómanos, centros de consejo y ayuda mutua para marginales de todas clases: grupos de encuentros diversos han sido improvisados por ellos ante las inéditas demandas. En su origen, estos recién llegados no pretendían ser los abnegados ayudantes de los especialistas competentes. En general, pertenecían ellos mismos a los grupos que querían ayudar. Denunciaban la rigidez y la estrechez de la formación psiquiátrica, su conformismo y su radical ineptitud para responder a las necesidades vitales de aquellos que buscaban una ayuda en su destreza. En los años sesenta se desarrolló en este sentido una ideología abiertamente antiprofesional...; en este momento la tendencia dominante es la «reprofesionalización" (Castel y otros, 1980: 285).

Este «descubrimiento» de la sociología radical francesa era ya evidente en las experiencias sobre educación «indigena» realizada por «indígenas» y sobre todo en una de las instituciones de autoayuda de más vieja data en Francia, pero cuyo proceso los sociólogos franceses más politizados e ideologizados se resisten a analizar: los grupos de autoayuda para alcohólicos. 
4. De lo analizado podemos concluir que existe una crisis del $\mathrm{MMH}$ y que una parte de esta crisis se expresa en su ineficiencia e ineficacia tanto respecto de los «nuevos" problemas de enfermedad (accidentes, contaminación, alcoholismo), como de los problemas «tradicionales» dominantes en nuestros países, aun cuando sean en términos teóricos los más simples de erradicar. Que en todas las áreas se ha generado un proceso de medicalización que incluye a los sistemas "tradicionales» aparentemente más aislados, a los cuales de hecho la medicalización ha «reconstruido». Que, en consecuencia, una posible solución radica en el desarrollo de sistemas alternativos, que por otra parte están sometidos a procesos de reapropiación constante por parte de los sistemas dominantes. Estos sistemas alternativos hallan su funcionamiento teórico-ideológico en las diferentes tendencias autogestionarias, tanto las emergidas estructuralmente en toda sociedad (medicina doméstica y comunal) como las planteadas como proyectos políticos y/o ideológicos a implementar.

Del análisis de los procesos que fundamentan la alternatividad surge: a) Durante los siglos xIX $\mathrm{y}$ xx se desarrolla una continuidad de tendencias autogestionarias que han fracasado permanentemente en el proyecto autónomo y han conseguido cierta permanencia en tendencias comunalistas marginales o en grupos de autoayuda, sobre todo en salud;

b) Las formas autogestionarias han sido planteadas desde las radicalmente autónomas hasta las que implican la "participación». Si bien las tendencias radicales cuestionan toda forma de participación, no niegan que comparativamente, como en el caso yugoslavo, supongan inicios de «democracia real». Marx ha reconocido la importancia de la autovaloración de la dirección laboral por parte de los propios trabajadores, aun cuando de hecho puedan ser «manipulados» por el sistema. El eje de la discusión consiste en reconocer a la autogestión radical como «la»'opción pero no negar en abs. tracto la legitimidad de procesos autogestionarios que pueden cumplir funciones de desarrollo hacia el propio control colectivo. El proceso de autogestión debe ser percibido como un fenómeno contradictorio, que no puede ser solucionado mecánicamente: «La autogestión es un concepto productivista surgido de las contradicciones del modo de producción capitalista a pesar de hundir sus raíces en los modos de producción anteriores. La autogestión se refiere a una racionalización del trabajo y, por extensión en tanto que auto. gestión generalizada, a una racionalización de la vida social. Pero, en vez de haber sido concebidas estas racionalizaciones como extrapolaciones de la organización científica del trabajo en dirección a la planificación y el control absoluto por parte de un centro, la autogestión otorga un contenido de socialización llevado hasta el límite de la racionalización; por consiguiente, un contenido de lucha contra el centralismo y contra toda planificación constituida por la propiedad privada de una casta de profesionales de la economía y de la polítican (R. Lourau, 1981:201);

c) Los procesos de reciprocidad simétrica, autoayuda, autogestión suponen la existencia de una serie de limitaciones funcionales que pueden tener consecuencias en la realización y, sobre todo, mantenimiento de los grupos que la asumen. Gran parte de las críticas ideológicas generadas sobre los "pequeños grupos» pueden ser referidas a este tipo de relaciones. Del análisis surge también que algunos principios de autorregulación grupal, a lo cual no escapa la autogestión, pueden operar conservadoramente. Toda reciprocidad supone compromiso entre los que la operan y exclusión respecto de los que no operan: «La creencia existencial en la reciprocidad y la nordad ponen las motivaciones egoistas al sedvicio de la estäbilidad del sistema social» (A. Gouldner, 1979:236). La reciprocidad y la autoayuda como control negativo y sobre todo como control de la diferencia es lo que no aparece incluido en los análisis que como los de P. Clastres rehabilitan la gestión homogeneizante de la reciprocidad primitiva. Si bien este autor reconoce que estas sociedades son centrífugas, y esto es un requisito de su unificación y homogeneidad, no reconoce que esto a su vez supone la eliminación radical de la diversidad;

d) La mayoría de los análisis señalan que todos los movimientos autogestionarios desde los cooperativistas y los grupos de autoayuda en salud hasta las tendencias gestionarias más radicales concluyen siendo absorbidos o destruidos por los sistemas dominantes. Esto es reconocido por las diferentes tendencias y consideramos que L. Maitan resume correctamente los diversos cuestionamientos: «Después las discusiones se agotaron y en algunos sectores de vanguardia se formaron tomas de posición bastante negativas, pero bastante difusas (hacia la autogestión). Para algunos la desconfianza, o la hostilidad declarada, dimanaba de un rechazo más general de los objetivos de naturaleza transitoria. Para otros, se trataba de un miedo pánico a la integración en el sistema, a la absorción, que les hizo colocarse en posiciones intelectualistas incapaces de actuar de manera alguna sobre el movimiento real de la clase. Otros más habían tenido en el pasado una concepción un poco mítica del control: habían creído en la posibilidad de una realización en un plazo relativamente corto, sin tomar en cuenta la situación general; conscientes al cabo de un tiempo de las lagunas de su concepción no se les ocurrió otra cosa que arrojar al niño con el agua del baño. Finalmente para otros la raíz del rechazo se encuentra en posiciones un poco snobs: lo "nuevo" los entusiasma, gozan un cierto juego intelectual y pasan a otros temas sin que ello se justifique por una reflexión crítica y $\sin$ haber llegado a la menor verificación prácticva» (1974:414). 
Ahora bien, la cuestión teórica central, no radica tanto en saber por qué los sistemas destruyen o absorben estas tendencias, sino en esclarecer si, pese a la absorción y destrucción, los mismos constituyen procesos legítimos hacia la realización final de los objetivos. Es obvio que respecto de las posiciones radicales la eliminación aparezca como una exigencia de los sistemas. O se las erradica o se las transforma; y la transformación se realiza hasta donde la autogestión sea compatible. Desde esta perspectiva, para algunos autores, el proceso de desarrollo capitalista, pero también los del «socialismo real» se encuentran en un conflicto cuyo límite lo constituye el poder. Les es necesario el aumento de la productividad, y tanto la teoría como la evidencia empírica les indican que el trabajo autónomo es más productivo. La cuestión es mantener el límite de esa autonomía más allá del poder de decisión. Este conflicto se halla favorecido por un proceso de reinstitucionalización que opera en todos los niveles de la cotidianidad y no sólo en el área laboral: «Lo que caracteriza al dominio del capital es que por lo general no se ejerce cotidianamente a través de relaciones de dominación, de relaciones violentas y de dominación política; sólo en períodos de crisis aguda del régimen la burguesía tiene que recurrir a estos medios de represión masiva para mantener su dominio. Normalmente dicha dominación se ejerce por medio de las relaciones mercantiles que todo el mundo acepta (incluidos los proletarios) como evidentes e inevitables ... Incluso los trabajadores que por el estudio, la reflexión, la educación política que han recibido y por su capacidad para extraer conclusiones generales de experiencias en luchas parciales, han comprendido que esas relaciones mercantiles no son en modo alguno «evidentes» $\mathrm{y}$ «naturales», que constituyen la fuente de todos los males dentro de la sociedad burguesa, y que, por tanto, pueden y deben reemplazarse por otras relaciones de producción; incluso estos trabajadores se ven obligados en la práctica cotidiana a tolerar, sufrir y reproducir las relaciones capitalistas si no quieren verse condenados a vivir al margen de la sociedad" (E. Mandel, 1974:16).

Dentro del pensamiento marxista esto ha sido principalmente teorizado por Gramsci, pero ha sido sobre todo la Sociología académica, ya sea funcionalista, interaccionista o marxista, la que ha demostrado hasta el hastío el peso, la «inercia», la determinación del sistema social, de la cultura, de la estructura. Es el trabajo cotidiano, «el oficio de vivir» el que actúa consciente e inconscientemente como el más fuerte erosionador ideológico (ver E. L. Menéndez, 1979 y 1981b). Es justamente en este trabajo cotidiano donde problemas como el del alcoholismo emergen como cuestionadores, pero no sólo de la ineficacia del $\mathrm{MMH}$, sino de estructuras sociales capitalistas y también socialistas que lo reproducen e incrementan al mismo tiempo que lo niegan. e) Para gran parte de los autores radicales la autogestión, el control real está planteado en términos absolutos: o se obtiene, o se pierde. Pero todo indica que la transformación es un proceso, una «brecha», como decía Marx, pero también varios autores en el 68: la «larga marcha a través de las instituciones», que decía Dutschke. Uno de los problemas radicales es asumir no el reformismo, sino que los procesos existen por encima de las crisis de crecimiento, de las coyunturas especiales. R. Lourau, analizando el proceso gestionario español de 1936, distingue dos momentos en la acción antiinstitucional: I) el no-institucional que supone la ruptura con el derecho y el orden estatal; y II) el contrainstitucional que supone la gestión directa por parte de las bases y no de la burocracia. «La originalidad de las colectivizaciones consiste en exigir una estrecha fusión entre los dos momentos de la acción antiinstitucional. Así se evitan los riesgos de la militancia idealista o burocrática así como los riesgos de aislamiento dentro de una transparencia microsocial fuera de las luchas populares» (1981:212). Ahora, a la pregunta ¿cómo se consiguió esto?, Lourau responde: «El concepto de colectivización no cae del cielo. Es en España donde la herencia secular de la responsabilidad colectiva de toda actividad social tuvo el mayor eco.... (1981:208). La cuestión está en cómo se aprende el control y la autogestión social, además de cómo se instaura y no sólo en la esfera laboral. Para muchos autores este proceso contradictorio no existe; toda alternativa se convierte en una suerte de «astucia del sistema»; desde esta perspectiva casi cualquier movimiento lleva a la inmovilidad. Así, dentro del campo específico de la práctica psiquiátrica todo puede ser absorbido; más aún, según el análisis de R. Castel, todo es absorbido y justamente los movimientos de autoayuda conforman la máxima expresión de la sintonía reguladora de estos grupos con el sistema. $\star \mathrm{El}$ éxito de este sistema perfectamente autorregulado sería que cada uno interiorizara la responsabilidad del control o fuera directamente llamado al orden por sus iguales. Evidentemente se trata de un ideal: amplios sectores de la vida social funcionan por medio de una represión ejercida por agentes exteriores a la colectividad afectada. Pero otros sectores, en número impresionante han recurrido a la convicción, al voluntariado, a la seducción, es decir al chantaje efectivo, a través de esta especie de empresas autogestionadas destinadas a reforzar la adhesión a los valores de la sociedad norteamericana y a difundir el conformismo que son las asociaciones filantrópicas, las sectas religiosas, las agrupaciones asistenciales, de apoyo, de ayuda mutua, de refuerzo moral y de consejo psicológico. Sería necesario un extraordinario despliegue de relaciones policíacas para conseguir el resultado que consigue casi espontáneamente el conjunto de todos los dispositivos de investigación, de vigilancia, de asistencia y de intervención 
preventiva, creados en nombre de una concepción filantrópica o científica de la salud y de la seguridad, con mucha frecuencia por unos intérpretes más auténticos de la mayoría silencoiosa o por unos investigadores más objetivos que si se hicieran a través de agentes pagados por el FBI o la CIA o incluso de los responsables de la aplicación de cualquier política oficial» (Castel y otros, 1980:295).

Este análisis tiene elementos ciertos, pero conforma una lectura unilateral, cerrada, no procesual; la institución aparece como un absoluto que todo lo absorbe. Avanzaríamos hacia una sociedad sobresocializada donde todos nos controlamos mutuamente. Y, por supuesto, toda sociedad hasta ahora basa en este principio su posibilidad de reproducción, la cuestión radica en detectar los factores conflictivos y contradictorios aun dentro de las sociedades que más conscientemente establecen estos mecanismos como principio de mantenimiento. Este tipo de análisis hace ininteligible la década de los 60 en los EE.UU. o el proceso polaco desde los 50 hasta la actualidad. No todos los mecanismos de solidaridad pueden ser usados para control. El propio proceso supone la emergencia de conflictos; de allí que algunos grupos de autoayuda, como algunas tendencias feministas puedan ser radicales.

Para nosotros en la discusión teórica de esta problemática existe una suerte de mal entendido inicial. Y este mal entendido radica básicamente en dos hechos: primero se da por concluido lo que constituye un proceso, y segundo, se pretende ver como exclusivo lo que es propio de los controles cotidianos de todo sistema.

Respecto del primer punto, lo que queremos significar es que algunos autores toman como acabado y fracasado lo que es un proceso constituyéndose no sólo en términos histórico-sociales, sino existenciales. Como dice E. P. Thompson: "La clase y la consciencia de clase son siempre, no las primeras fases del proceso real histórico. Pero, si empleamos la categoría estática de clase, o si obtenemos nuestro concepto del modelo teórico previo de una totalidad estructural, no lo creeremos así: creeremos que la clase está instantáneamente presente (derivada como una proyección geométrica de las relaciones de producción) y de ello la lucha de clases ... Todo este escuálido confusionismo que nos rodea (bien sea positivismo sociológico o idealismo marxista-estructuralista) es consecuencia del error previo: que las clases existen independientemente de relaciones y luchas históricas y que luchan porque existe, en lugar de surgir su existencia de la luchan (1979: 37-38).

- La autogestión radical se aprende en los procesos fracasados de cooperativas, de comunalismo, de ayuda mutua, de participación, de cogestión; se aprende de los fracasos y de las escasas coyunturas de «éxito». ¿Qué sabe- mos realmente de la ideología política, o si se prefiere, como dice Thompson, de la "economía moraln de los grupos de autoayuda, pero también de los trabajadores alemanes de 1953 y de las comunas de la vida de los 60? La trama ideológica que funda parcialmente sus acciones la conocemos más que nada en el nivel manifiesto, y no en el nivel que las determina.

El segundo punto se refiere a que todas ias estructuras establecen regulaciones internalizadas, ya que todas asientan su dominación básicamente en éstas. El poder coercitivo es lo excepcional y no lo cotidiano. Justamente las sociedades más exitosas en este control interno y cuasi total han sido las sociedades "primitivas», eliminadoras de la diferencia. La posibilidad de control interno, si ha fracasado en alguna situación, lo ha hecho en las sociedades actuales; de ahí que sólo ahora la psiquiatría tiêne no sólo una, sino varias antipsiquiatrías. ${ }^{3}$

Para concluir, subrayamos que la problemática salud/enfermedad/atención constituye, tanto en términos estructurales «constantes» como en términos de una emergencia no solucionable ni a nivel estatal ni monopólico privado, un área donde el proceso autogestionario puede significar una alternativa embrionaria y nuclear de otras alternativas, como incipientemente ocurre con determinados grupos feministas o con ciertos tipos de grupos AA.

En este artículo se ha pretendido establecer los fundamentos conflictivos de dicha alternativa, así como un esquema de la trayectoria de los movimientos políticos y sociales que se han hecho cargo de la misma.

En trabajos sucesivos trataremos de analizar el desarrollo de las alternativas autogestionarias en salud, tanto en el nivel dado de toda sociedad, como en aquellos casos en que emerge como una propuesta política y social global (movimientos feministas).

Debe quedar explícitamente claro, que las propuestas alternativas de autoatención, no suponen la negación del desarrollo técnico y científico, sino, por el contrario, la propuesta de la apropiación social de dicho desarrollo.
1. En este trabajo no trataremos los desarrollos autogestionarios generados a
artir de la comunidad y desarrollados, metropolitanas, como en aquellas donde se dan procesos de descolonización 
2. Al respecto, es importante subrayar que, tanto en el período del temprano desarrollo industrial capitalista como durante la década de los treinta, serán la protosociología y la sociología académicas, las que retomen el problema de la importancia del «pequeño grupo». Esto es aún más relevante, porque ocurren en períodos de notable pauperismo de la clase obrera y del campesinado, en periodos en que se hace evidente la quiebra de los «grupos primarios tradicionales», en períodos en que el Estado se relaciona con los individuos casi sin intermediarios. Que en estos mismos periodos las prácticas políticas radicales, salvo excepciones, se hayan negado a pensar la importancia politica de otros grupos primarios, que mediatizaran y esuperarans al Estado, implica los límites teóricos, ideológicos y prácticos de sus concepciones políticas y sociales.

3. Este análisis no implica negar los mecanismos de control basados en la coacción física, sino señalar el carácter secundario de los mismos en la estructura cotidiana.

\section{BIBLIOGRAFIA}

AtTALI, J,

1981

El orden caníbal. Vida y muerte de la medicina. Barcelona, Planeta.

BabeaU, A.

1968 Los consejos obreros en Polonia. Barcelona, Nova Terra.

BAHRO, R.

1979 La alternativa. Critica del socialismo realmente existente. Barcelona, Materiales.

BLAXTER, M.

1978 Diagnosis as category and process: "The case of alcoholism". Social Science \& Medicine, 12:9-18.

BOURDET, Y

1977 Karl Marx y la autogestión». Cuadernos de Pasado y Presente. México, 33:57-74.

BRAVERMAN, H.

1975 Trabajo y capital monopolista. La degradación del trabajo en el siglo XX. México, Nuestro Tiempo.

Calderón, G.; Campillo, C., y Suírez, C.

1981 Respuestas de la comunidad ante los problemas relacionados con el alcohol. México, Instituto Mexicano de Psiquiatría.

- Castel, F.; Castel, R., y Lowell., A.

$1980 \quad L a$ sociedad psiquiátrica avanzada. El modelo norteamericano. Barcelona, Anagrama.

Clastres, P.

1981 «a cuestión del poder en las sociedades primitivas», InvestigaCRAWFORD, R. ciones en Antropologia Politica. Barcelona, Gedisa.

1977

You are dangerous to your health: «The ideology and politics of victim blanding». I.J.H.S. 7(4):663-79.
EDWARDS, G.

1980 «Alcoholism Treatment: Between Guesswork and Certainty». En: G. EdWARDS y M. Grant (edits.), pp. 307-320.

Edward, G., y Grant, M.

1980 Alcoholism Treatment in Transition. London, Croom-Helm.

Elizondo, J.; Macías, R., y Ramírez, A.

1977 «Aspectos médico-psiquiátricos del alcoholismo». En: A. Guerra,

Foucault, M.

1979 Historia de la locura en la época clásica. México, F.C.E., 2 vols.

1977 «Historia de la medicalización». En: E.M.S. 11(1):3-25.

Guetarkama, B., y otros

1977 «Consejos obreros y democracia socialista». Cuadernos de Pasado GOULDNER, A,

1979 Gross, M. L.

1978 La falacia de Freud. Madrid, Cosmos.

GUERRA, A.

1977 El alcoholismo en México. México, F.C.E.

Gvishiani, D.

1973 Organización y gestión. Moscú, Progreso.

HeATHER, N.

1978 Perspectivas radicales en psicologia. México, Continental.

INFIELD, $\mathrm{H}$.

1959

Utopia y experimento. Ensayo de una sociologia de la cooperación.

JAFFE, J.

1980 Buenos Aires, Cía, Fabril Editora.

LOURAU, R.

1981

"What Alcoholism Isn't Borrowing», en G. Edwards y M. Gran] (edits.), pp. 32-48.

MAITAN, L.

1974 «El movimiento obrero en una fase crítica, en E. MANDEL, pá-

MANDEL, E.

1974 Control obrero, consejos obreros, autogestión, México, Era.

MatTick, $\mathrm{P}$

1977

MeISTER, A.

1969

entrol obreros, en P. MatTick y otros: Los consejos obreros y la cuestión sindical. Madrid, Castellote, edit., pp. 51-90.

Los sistemas cooperativos: ¿Democracia o tecnocracia? Barcelona, Nova Terra. 
Melville, K.

1980 Las comunas en la contracultura. Origen, teorias y estilos de vida. Barcelona, Kairos.

MENÉNDEZ, E. L.

1960 "Colonialismo, neocolonialismo: Racismo". Indice, 6: 72:93.

1978 «El modelo único y la salud de los trabajadores», en F. BASAGLiA y otros: La salud de los trabajadores. Nueva Imagen.

1979 Cura y control. La apropiación de lo social por la práctica psiquiátrica. México, Nueva Imagen.

1980 «Los modelos médicos y la práctica médica. Conflicto, contradicción y transacciones», en L. CAÑEdo y O. Pedrotra: Salud y Enfermedad en México.

1980a La automedicación y los medios de comunicación masiva». Cua dernos Médico-Sociales, 15: 33-34.

1981b Poder, estratificación y salud. Análisis de las condiciones sociales y económicas de la enfermedad en Yucatán. México, Ediciones de la Casa Chata.

1982 «Medios de comunicación masiva, reproducción familiar, formas de medicina popular». Cuadernos de la Casa Chata, 57, México.

Menéndez, E. L., y Di Pardo, R. B.

1981 Alcoholismo. Definición diagnóstica, clasificaciones e indicadores. Revisión crítica. Ms.

MOSER, J.

1978a The crisis of the Western System of Medicine in Contemporary Capitalism, en IJHS, 8(2): 179-210.

NAVARRO, V.

1978b La medicina bajo el capitalismo. Barcelona, Grijalbo.

NEGRI, A.

1980 Del obrero-masa al obrero social. Entrevista sobre el obrerismo cargo de P. Pozzi y R. Tomasini. Barcelona, Anagrama.

O.M.S.

1980 Problemas relacionados con el consumo de alcohol. Inf. Técnico N. ${ }^{\circ} 650$, Ginebra.

ROBINSON, D., y HENRY, S.

1977 Self-Help and health-mutual aid for modern problems. London, Martin Robertson.

RoszaK, Th.

1981

El nacimiento de una contracultura. Barcelona, Kairos.

SLANSKY, R.

1969

"Los primeros pasos de la autogestión en una fábrica checa de construcciones mecánicas», en Autogestión en Checoeslovaquia, Zero: $24-41$.
THOMPSON, E. P.

1979 Tradición, revuelta y consciencia de clase. Estudios sobre la crisis VELAZCO, F. R de la sociedad preindustrial. Barcelona, Crítica.

1977 «Programa de acción contra el alcoholismo y el abuso del alcohol». en A. GUerRA, pp. 161-170. 